\title{
The Development of FL Teachers' Professional Identity through the Production of Narratives
}

\author{
Cristina Pérez-Valverde \\ Raúl RuIZ-CECILIA \\ Universidad de Granada
}

Received: 28 September 2012 / Accepted: 3 December 2013

ISSN: $1697-7467$

\begin{abstract}
This paper presents a pioneering teacher training model based on the development of teacher identity. We examine the planning and steps carried out in the implementation of a research project financed by the Spanish Ministry of Science and Innovation (Spain). The first phase focuses on the trainees' own narratives. We also used questionnaires, interviews, and held weekly seminars to elicit information from a multifaceted point of view. Results show agreement with theoretical predictions and match former studies outcomes. The work presented here has profound implications for future studies of teacher training, and shows evidence in the development of participants' critical thinking and reflective capacity. Keywords: Extensive narratives, language learning, teaching identity, otherness.

EI desarrollo de la identidad docente del profesorado de LE mediante la producción de narrativas

RESUMEN: El presente artículo presenta un modelo pionero para la formación de profesorado basado en el desarrollo de la identidad docente. Se examina el planteamiento y las diferentes fases que se llevaron a cabo en la implementación de un proyecto de investigación financiado por el Ministerio de Ciencia e Innovación (España). La primera fase utiliza las narrativas de los propios maestros, las cuales se complementan con cuestionarios, entrevistas y seminarios semanales con el fin de obtener información desde una perspectiva multifacética. Los resultados coinciden con las predicciones teóricas y corroboran los resultados de trabajos previos. Este estudio tiene profundas implicaciones para futuras investigaciones sobre la formación de docentes y aporta datos que ratifican el desarrollo del pensamiento crítico y de la capacidad reflexiva de los participantes.

Palabras clave: Narrativas, aprendizaje de lenguas, identidad docente, otredad.
\end{abstract}

\section{INTRODUCTION}

The narrowing of the gap between theoretical instruction and professional training in teacher education has long been a challenging issue. During their in-class placements, trainees often comment on the need to improve their professional competence to successfully overcome the difficulties arising in the school environments, not only in relation to behavioural, organizational or pedagogical questions of a general sort, but also regarding the teaching of their own subject matter, in the case of students preparing to become specialist teachers. 
This is particularly so in the face of the multicultural, inclusive models prevalent in many European schools at present.

We are being witness to quick changes in society. Such changes have a clear effect upon school life, and call for a reorientation of educational methods and measures. The development of multicultural communities, the impact of technology and globalization are some of the issues currently demanding the attention of teachers, teacher educators, and educational authorities.

In light of the above, the need for reflective practitioners seemed to us clear. Future teachers should, in our view, be able to construct and negotiate their professional competence in accordance with the particular requirements of their educational environments. Besides, a proper teacher training programme must help students build their own teaching identity taking into consideration current challenges, such us gender and intercultural issues, diversity, and bullying.

Therefore, we embarked on a project aimed at increasing self-awareness through reflection and critical questioning, as a starting point for further professional development on the part of our teacher students. The project was entitled "Implementing a model based on self-awareness, teachers' identity and existential competence in the training of FL teachers"'. We sought to develop appropriate techniques and instruments oriented to help them identify and explore their beliefs and attitudes towards the teaching profession, as well as to diagnose their own strong points and weaknesses. The general idea was to bring to the fore the vocational aspects in teacher education, particularly so with respect to attitudes, abilities and values, as a means to counterbalance the prevalence of theoretical contents in the teaching curricula. Thus, our project was aimed at testing the validity of a Foreign Language teacher training model based on the development of teacher's identity awareness, or trainees' selfconsciousness about their own professional development, and focused on the capacity of language pedagogy to improve the harmonious growth of the individual within society.

The project paid special attention to the existential issues involved in the process of learning a new language. According to the Common European Framework of Reference for the Teaching of Languages, existential competence comprises all those areas which affect the individual and social development of a person. We particularly focused on the following:

- Perception of others, or encounter with otherness: questions of gender, intercultural issues, diversity, and bullying, basic aspects implicit in the construction of the person as a social being.

- Identity, perception and construction of the self. Being in contact with a new language generates a number of processes and reactions, not only of a cognitive, but also of an affective nature, which influence the construction of the self (Arnold 1999, MacIntyre \& Gardner 1991, Wakamoto 2000). These processes must be carefully guided, so as not to interfere with the students' development and to contribute to the enrichment of their personality. 62329)

${ }^{1}$ This research is part of a project financed by the Spanish Ministry of Science and Innovation (SEJ 2007-

\section{2}


The initial hypotheses were as follows:

- Providing trainees with the appropriate techniques and strategies to supervise their own evolution will significantly contribute to the improvement of their development, in a double sense: a) by activating their teaching skills; and b) by enabling them to envisage the foreign language as an instrument potentially able of contributing to the integral development of the individual.

- The reinforcement provided to the subjects participating in the study through the intervention programme will significantly influence their learning results, and will entail better outcomes at the end of their training in relation to their own peers.

- By virtue of its transferability and applicability to other environments, the training of teachers in general will be substantially benefited with the implementation of the new model tested and presented. In this sense, our work will provide relevant data in the context of educational research, language teaching, and teacher training.

A longitudinal research was conducted with a group of students throughout their three years of University training. The development of the participants during the intervention programme was assessed through portfolios, life stories, and interviews. Thus, a qualitative narrative approach was followed. This way, we intended to implement in our own educational environment a model that had already been implemented in a successful way in other Teacher Training Centres throughout Europe.

\section{BACKGROUND RESEARCH AND PREVIOUS STUDIES}

The present research took into consideration the key findings of a previous European project, aimed at designing instruments oriented to help students identify and explore their beliefs and attitudes towards the teaching profession. A network of teacher educators from seven countries worked together with a view to enhancing the education of teachers in the context of an integrated Europe. Seven Universities were involved, including our Faculty of Education in Granada ${ }^{2}$. The early steps entailed a comparative analysis of the processes of teacher training in each of the partner countries. This analysis evidenced the convenience of devising alternative models in order to enhance students' self-assessment, a measure that was already in practice in two of the participating institutions: Offenburg (Germany) and Lulea (Sweden). The need for the construction of a 'teaching identity' from the beginning of the students' career was highlighted, as well as the importance of bringing out the potentials of the person in a holistic sense. The ultimate impact of the European project was to provide teacher students with a deeper understanding of their personal motivation entering the profession and with insights into the aspects of teaching competence that lie beyond knowledge of one's subject (Hainmuller 2006).

The self-diagnosis model in the initial training of teachers has successfully been implemented in other European institutions. Jokinen \& Saranen (1998) conducted a research

\footnotetext{
211].

${ }^{2}$ APT (Appraisal of Potential for Teaching”- 2003/07), Comenius 2.1 [112438-CP-1-2003-DE-Comenius-C-
} 
project that proved the benefits of such a model. The research was carried out in Jyväskylä Teacher Training School, with a group of students in the subject of Maths Teaching. Data were gathered through diaries and observation. The authors emphasized the need to develop self-assessment strategies and promote critical capacity from the early stages of teacher training, so as to enable future professionals to face the particular demands of a diverse range of educational environments (see also Heikkinen, Jokinen, and Tynjälä, 2012).

Of special interest is a research project conducted by Nissila $(1999,2005)$, who -also in the Finnish context- analysed the development of critical capacity, reflective skills, selfunderstanding, and professional identity awareness in a group of teacher students. The participants were asked to reflect on their beliefs, memories, pre-conceptions, values, feelings and expectations, as well as on subject matter knowledge, general methodology, and pedagogy issues, basically through portfolios and diary writing. The findings of the study point to the necessity of seeing professional growth to autonomy as a dynamic, active process, whose elements are commitment, enquiry, and reflection (Nissila 1999: 15).

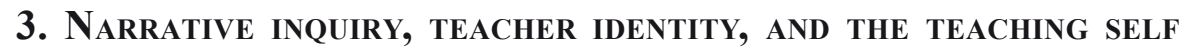

'Teaching identity' and 'teacher self' are key concepts in our study. In their in-depth study of research on teacher identity formation, Beijaard, Meijer and Verloop (2004) concluded that most researchers considered professional identity as an ongoing process of integration of the 'personal' and the 'professional' sides of becoming and being a teacher. For Volkman \& Anderson (1998), the teaching identity entails a complex and dynamic equilibrium where professional self-image is balanced with a variety of roles teachers feel that they have to play. In Bullough's view (2008), teacher education must begin by exploring the teacher self. In the same line, for Bolívar, Domingo and Fernández (2001) those elements making up the individual self, in the existential sense, such as beliefs and values, intuitions, and principles, should be the basis of teacher training.

The self appears to be inseparable from a person's narrative or life story (Kerby 1991). Through the very act of telling, the person shapes his or her own self. Therefore, the production of autobiographical narrations and life stories is recommended both as a formative and a research tool (Pérez-Valverde \& Ruiz-Cecilia, 2012). In this regard, the narratives produced in our project by the student teachers were not only envisaged as a hermeneutic tool to unearth meanings or obtain data (that is, as a research tool), but mostly as a fundamental asset in the process of becoming teachers, that is, in their acquisition of a 'teacher identity'. This dual nature of the narratives, both as formative and research tools, is very much in accordance with the narrative inquiry procedures, and the narrative research in education methodologies, approaches that are at the basis of our research.

For Kearney (2002), subjectivity and identity are negotiated through narratives. Narratives enable us communicate to others who we are, and cast light on life experiences. So identity can be interpreted, from a narrative point of view, as the story or account that one tells about oneself, having as backdrop the discourses one is part of. 


\section{Methodology}

\subsection{Context and participants}

The study was conducted in the Faculty of Education, University of Granada, during the years 2007/10. The subjects were twenty students in the degree of Primary Teaching, specialising in English or French. Two of the participants came from another degree in Education and were specialising in English teaching. Two other students were older than 30 and had accessed to University after years in the labour market. Another student, whose mother tongue was French, came from a French University, and was 27. The rest of the participants were students aged 18 to 21 who had access for the first time to college. Participants in the study agreed to it in an entirely voluntary basis, after a briefing where the philosophy of the project was explained.

\subsection{Instruments and procedures}

As has already been said, our research was grounded on the narrative approach, which considers narratives as essential tools to understand and construct reality. The instruments chosen were those of the life story and the portfolio, both used as reflective, metacognitive tools. Besides, a webpage was created and maintained in order to build a choral narrative and discuss specific issues of general concern to participants (www.identidaddocente.es). The written reports were complemented with oral narratives through seminars and interviews.

Below is a description of the instruments and procedures employed to conduct the study.

(a) The life story or initial narrative: The life story was defined by Denzin (1989) as autobiographical narration, account by the protagonist of own life or fragments of life, personal narrative, a story of personal experience. Through the life story, the subject becomes the object of knowledge, and co-researcher of his/her own experience. Life stories, and biographies in general, make sense of the cognitive, affective, and attitudinal dimensions of the individual.

In the second semester of their first year, students were asked to write a text recounting the role of teaching and education in their lives, so as to face their own memories, ideas, attitudes, pre-conceptions, experiences, and expectations. The text should include the following aspects:

- Early experiences at school

- Role of teaching throughout own life, focussing particularly on the reasons for choosing this profession

- Experiences during training period

(b) The portfolio: Throughout the three years of the study, the participants elaborated a portfolio, which served as an appraisal instrument for the trainers, but mostly as a selfassessment and metacognitive tool for students. Organised in the manner of a diary, the portfolio gathered observations, reflections, meaningful events taking place during this period (in particular, during in-placement in schools in the third year), and analysis of such events. 
(c) Interviews: The interviews were conducted at the beginning of the first year, although later on students went through them again at different stages. The interviews designed comprised the following categories of questions:

- Personal vision and attitudes regarding the teaching profession.

- Knowledge of educational contexts and realities (present challenges, main problems faced by teachers...).

- Competencies related to the teaching of English/French, both linguistic and didactic.

- Personal reflection on current challenges and educational needs (gender issues, diversity, bullying, multiculturalism, education for peace), bearing in mind the possibilities of language teaching and learning to humanise relations within society.

- The affective domain in the construction of the teaching self (existential questions related to their feelings, emotions, uncertainties, and level of satisfaction with their professional development).

(d) Weekly seminars: The whole team met on a weekly basis (trainers/researchers and trainees). The seminars were oriented to creating a common space in which experiences were shared and problems discussed, particularly so during the students' teaching period. The participants had the chance to discuss and analyse their reflections and responses when confronted to the reality of the classrooms. A number of key issues arose during the sessions, evidencing their concerns while witnessing and participating in the foreign language lessons at schools.

\section{Analysis of results}

This research study springs from the bases of qualitative methodology according to which the knowledge and analysis of the human experience makes sense if tackled from the subjective lens of those having an active role in it. It is highly illustrative the metaphor used by Schostak (2002: 5), who defines the research project in terms of a journey, whose preparation implies making decisions about the means of transport. Provided that the goal is to have a closer view of the immediate environment, then we must go on foot instead of taking the car. Even so, in order to understand the lives of people who venture on the well-trodden paths, it would be necessary to approach them, observe their habits, establish contacts, initiate conversations, listen to their voices, their biographies, their ways of seeing the world.

Concurrently, the notion of 'qualitative research' goes beyond the mere use of data collection methods or the disposition of these in their textual form.

The analysis and interpretation of the results have been carried out in the light of the data taken from:

a) Extensive narratives.

b) Questionnaires and seminars.

c) Direct observation from the research team. 
d) Objective data which reflect the target group's improvement.

e) External participants (principals and schools' mentors)

f) Participants' self assessment.

In the first stage, we analysed the participants' initial life stories. These set the starting point in the construction of the subjects' teaching identity. The pivotal idea was to sequence events and circumstances of their academic careers, and to make sense of all the elements which constitute the individual biography in terms of education. According to Pineau \& Le Grand (1993: 100-2), there are three approaches to life story analysis:

a) External analysis, in which the interpretation is conducted by an evaluator/teacher, etc;

b) Self-analysis: the analysis is carried out by the producers of the life story, and

c) Dialogical model or cooperative approach, which is the one followed in our project. The philosophy behind is to make the implicit explicit as a collaborative task. The analysis requires the collaboration of the researcher to elicit the sense and coherence. It enables the student (writer) to take distance from his or her own life, while allowing the researcher to get a close look at it.

Bearing in mind the dialogical model, participants were requested to read their narrative closely before writing down their conclusions about the role of education in their lives and the reasons why they have decided to become teachers. Next, the research team delivered a template with categories to each participant. This template was developed within the European Project Comenius mentioned earlier. In this project, we worked with life stories written by would-be teachers and were analysed similarly. The analysis of these extensive narratives revealed the existence of common patterns. The recurring topics were then systematized and reduced to a set of categories.

With the help of the aforementioned template, each participant proceeded with the analysis of his or her narratives in terms of omissions or not of the topics. They were encouraged to reflect on the connections between past experiences, currents needs and future wishes.

One of the most telling and recurring evidence is that participants considered school years as a key element in the understanding of the teaching identity. All the participants responded to this point in a very emotional tone. They main areas of interest pinpointed were their positive or negative memories of schools, in particular of their teachers, who exercised a great influence over their personal development. Some examples are:

"First of all, let us consider the importance of teachers, since they are essential to condition us for the future. I remember that the majority of my teachers explained and taught really well, but others were too hard with us if we consider our ages. I believe that the teacher has an important role, because at these early ages everything you learn prepares you for life, and the concepts that you learn are the basis of your future knowledge. When I was in Primary, my English teacher was a really good professional. She gave us lots of affection, and used games and songs to explain concepts, such as the numbers, the alphabet, etc. For this reason, I always liked English." 
"When I was nine, I had one teacher who I did not like [...] So, I thought that if one day I became a teacher I would never let my children get bored or do something that they do not enjoy."

"I am going to talk about the memories of my childhood. I have in my mind many of them that I will never forget. Let us start with the unforgettable memories that I have from school. One example would be when L., who was my Primary teacher, taught us how to enhance our intelligence by reading interesting books. He also taught us the basics to be able to solve mathematical problems. I did my best to become the best student in this subject."

The figure of the teacher seemed to have influenced greatly their decision to become teachers. School experiences worked as the driven force in most of the cases, whether to recreate a fair school context or to counteract a negative memory from school years. As an example, we would like to refer to a student who confessed to having been humiliated by a teacher. Later on, when he was questioned about his strengths, he answered: "being close to students, readiness to help, providing support and being able to surmount difficulties." And when he was asked to narrate a meaningful episode of his teaching practice, he replied: "I was delighted when I presented my unit of work; I paid special attention to children with behavioural problems."

When it comes to the analysis of life stories, we applied a set of categories that was formerly developed in our previous Comenius project (after observing a set of common patterns in the life stories of former students). Such categories were as follows:

a) Memories of relevant events and their influence in their professional choices (meaningful episodes, influence of positive teaching figures, rejection of negative figures...). For instance, "I remember my teachers as big pupils, full of knowledge. That implies a sort of indirect respect to them because some were also like friends." (Positive image of teacher).

b) Family tradition: other members of the immediate family or social circle work as teachers (parents, aunts, uncles, grandparents, neighbours).

c) Ethical, humanitarian reasons (vocational aspects: the will to help people to learn; working with children; improving social and human conditions...). One of the participants affirmed: "I studied teaching because I think education is very important for human beings, as it is a great means of liberation from ignorance and manipulation."

d) Cognitive factors: preference for a subject, interest in the tasks involved in the teaching professions such as management or leadership. For instance, one of the trainees stated: "I have realised what a human profession this one is. Contact with other people transforms you. You gain patience and comprehension. It is much more fulfilling and rewarding than working in an office." Another one wrote: "I have always like English and I want to teach it to children."

e) Practical considerations: duration of studies, long holidays, the teaching degree as second or third choice to access university.

f) Influence of external factors (family, society): economic motivation (correlation between the families' social status and the choice of university studies), or gender roles and stereotypes (popular degrees for men or women). 
It is important to note that none of the 20 participants decided to study teaching guided by reasons illustrated in categories e or $\mathrm{f}$. Most of them combined aspects under a, c, and d. However, we were surprised to find that some of them belonged to a family of teachers. Besides, as a consequence of the group heterogeneity in terms of age and earlier training, the reflections of participants showed varying degrees of thoroughness. It was observable, for example, that mature students tended to justify their choice of a course of study emphasising the social and humanistic aspects involved in it.

Each participant met with his or her mentor to reflect on the data generated in this first narrative about teaching identity. These data were completed with the information gathered in the recorded interviews (with the written consent of the participants) and then transcribed.

Firstly, we analysed the recorded material since it depicted meaningful codes from oral communication, such as reiterations, hesitations, intonation patterns, etc. Later on, we utilized transcriptions as the bases to establish the interviewee's profile. This furnished us with crystal-clear information which helped us to obtain a better view of the participants. It also facilitated the comparison of participants' responses.

Next we systematized the data in a chart and added comments, in the form of short narratives, to catalyse interpretation of individual stories. This enabled us to keep the wholeness of the narrative even if the information was transferred to a chart. Thus we embarked on a two-folded analysis to interpret the data: vertical, or the study of each individual biographic profile, and horizontal, or the systematic comparison of different profiles.

The interview results were discussed on individual meetings held afterwards. This permitted us to collate the interview data and the initial life stories. In this way, each participant builds and rebuilds his or her professional identity, and is monitored by his or her tutor.

The interviews revealed that vocational reasons and positive attitudes towards teaching were decisive, even though there were important differences with regard to the participants' analysis capacity and the profoundness of their reflections. At the same time, students became aware of their linguistic competence in the foreign language and were committed to improving their language proficiency level.

Another major source of data lies in the observation carried out by the research team. We observed that the participants' improvement was more evident in the third year. Their participation in the seminars showed great advances in the use of English. The interest for learning disclosed through the whole project and the positive attitude towards the reflective and metacognitive strategies resulted in a significant transformation. This was more evident in those participants who initially evinced a great deal of difficulty to articulate judgments and reflections through critical disclosure. In general, we can affirm that participants turned into sensible and responsible professionals who prioritized long life learning as an asset. They claimed themselves to be fully aware of what being a teacher entails. In this sense, at the end of the third year, the research team organized a conference ${ }^{3}$ focused on narratives and teaching identity for language teachers. The main protagonists were the twenty students who took part in the project from the very beginning. They chaired panel discussions and addressed conferences.

3 I Conference of Language Teachers' Narratives: the Existential Competence. Granada, Faculty of Educational Studies, from May 12 to May 14, 2010. 
This was envisaged as a landmark in our institution as we put students in the spotlight. The experience may be interpreted as cogent evidence of their entrepreneurship.

In addition, the target group developed a heightened sensitivity to existential issues within the area of foreign languages. A significant number of seminars were devoted to the search of teaching material to come to grips with existential competence. The participants designed projects and activities which were then implemented in schools during their practicum period.

Feedback was collected from school professionals who mentored our target group in the schools. Each of the school teachers and principals submitted a report which provided us with valuable information for the improvement of our model.

$[\ldots]$ if we compare teacher trainees from previous years to the ones participating in your project, we must highlight their attitude. They are, by far, more involved in teaching, in school activities, in school life in general. My colleagues and me have commented on it on several occasions. Their attitude is very positive [...] The main difference lies on the fact that they come to the school with ideas, with creativity. They will become excellent teachers: hardworking, responsible and with a love for their job $[\ldots]$. We think that your project is noteworthy and very well coordinated with schools and with English teachers. School practices regain their status after having been losing ground for decades. (School's Headmaster).

Finally, participants were also requested to write down a final evaluation report on how the project went and a self-evaluation of their participation and evolution. All the participants recognized the worth of the project and highlighted the numerous benefits for them as future teachers.

This project about teaching identity contributed greatly to improve our understanding of teaching values. The project's philosophy is all embracing. On the one hand, we have experienced in the first person what teaching means in actual schools. On the other hand, envisaging narratives as a self-training tool prompted a great change of perspective. Thanks to the project, my teaching practices at Alquería School turned into a memorable learning experience worth of entering my list of special moments.

\section{Conclusions}

After having analysed all the data collected, we can affirm that the participants were highly benefited with the information and experience gained during the duration of the project. The most remarkable are:

- Improvement of students' linguistic competence in the foreign language, especially for those with the lowest level at the beginning of the project (four of the participants had failed English/French in the first year, and some more courses related to the study of the foreign language; however, all of them passed those subjects in the third year).

- Development of their reflective capacity and critical thinking.

- Development of their self-evaluation capacity. 
- Familiarization with strategies to improve their linguistic and teaching training.

- Development of their ability to express and articulate ideas in public.

- Development of their written competence and their ability to connect ideas and concepts.

- Awareness of how otherness and diversity issues can be handled in class. Language is envisaged as a tool to foster understanding and to attempt at personal development, both in an individual and social sense.

On the other hand, a horizontal analysis of the results points out that:

- This project has fulfilled the existing pitfalls for future language teachers at university level. Their narratives showed that those courses focused mainly on theory did not contribute to the development of the holistic training.

- This intervention project had a major impact on the development of students' teaching abilities, and raised students' awareness about the importance of teaching.

- According to the target group, there is not a parallelism between students' vocation for teaching and their academic performance. They usually lack competence in the foreign language. However, whenever they are given the opportunity to reflect on their weaknesses and how they can be overcome, they succeed in their achievements. Hence, motivation plays a decisive role in this process.

As a whole, we have showed the validity of our training mode (which had already been implemented in other foreign universities) as part of the programme of studies to become a teacher. It would be recommendable to integrate this model in the faculties of education all over Spain since the present system does not match students' needs. Our study bets heavily on the supply of the needed infrastructure in order to monitor and tutor students individually from the very beginning. This would be the only way to educate would-be teachers in a responsible manner, and to prepare them to deal with present educational challenges.

\section{REFERENCES}

Arnold, J. (ed.) (1999). Affect in Language Learning. Cambridge: Cambridge University Press.

Beijaard, D., Meijer, P.C., and Verloop, N. (2004). "Reconsidering research on teachers' professional identity", in Teaching and Teacher Education, 20: 107-128.

Bolívar, A., Domingo, J., and Fernández, M. (2001). La investigación biográfico-narrativa en educación. Madrid: La Muralla.

Bullough, R.V. (2008). Counternarratives: Studies of Teacher Education and Becoming and Being a Teacher. Albany, NY: State University Press of New York Press.

Council of Europe (2001). A Common European Framework of Reference for Languages: Learning, Teaching, Assessment. Cambridge: CUP.

Denzin, N.K. (1989). Interpretive Biography. Newbury Park, CA: Sage.

Hainmuller, B. (2006). "Exploring Values in Teacher Education", in M. Persson (ed.), A Vision of European Teaching and Learning: Perspectives on the New Role of the Teacher. Karlstad: Learning Teacher Network, 115-130. 
Heikkinen, H., Jokinen, H., and Tynjälä, P. (2012). "Teacher education and development as lifelong and lifewide learning", in H. Heikkinen, H. Jokinen, and P. Tynjälä (eds.), Peer-Group Mentoring for Teacher Development. London: Routledge, 1-30.

Jokinen, H. and Saranen, E. (1998). "Development of students' teachers self-assessment", in Hannu Jokinen and John Rushton (eds.), Changing Contexts of School Development - The Challenges to Evaluation and Assessment. Jyväskylä: Institute for Educational Research, $1-18$.

Kearney, R. (2002). On Stories. London \& New York: Routledge.

Kerby, A. (1991). Narrative and the self. Bloomington, IN: Indiana University Press.

MacIntyre, P.D. and Gardner, R.C. (1991). "Methods and results in the study of anxiety and language learning: A review of the literature", in Language Learning, 41,1: 85-117.

Nissila, S.P. (1999). "Reflective practice in Teacher Education and the need for autonomy", in A. Camilleri (ed.), Introducing Learner Autonomy in Teacher Education. Germany: Council of Europe Publishing.

Nissila, S.P. (2005). "Individual and collective reflection: How to meet the needs of development in teaching." in European Journal of Teacher Education, 28(2): 209-219.

Pérez-Valverde, C. and Ruiz-Cecilia, R. (2012). "Paving the way towards the ECTS system: Self-assessment, metacognition, and professional competence in a literature course for FL teachers", in Porta Linguarum 17, 67-77.

Pineau, G. and Le Grand, J.L. (1993). Les histoires de vie. Paris: PUF.

Schostak, J. (2002). Understanding, Designing and Conducting Qualitative Research in Education. Philadelphia: Open University Press.

Volkmann, M.J. and Anderson, M.A. (1998). "Creating professional identity: Dilemmas and metaphors of a first-year chemistry teacher", in Science Education, 82, 3: 293-310.

Wakamoto, N. (2000). "Language learning strategy and personality variables: focussing on extroversion and introversion", in International Review of Applied Linguistics IRAL 38,1: 71-81. 